\title{
Characterization of Novel Lactobacillus paracasei HY7017 Capable of Improving Physiological Properties and Immune Enhancing Effects Using Red Ginseng Extract
}

\author{
Sung-Joon Mo $\mathbb{B}$, Bora Nam, Chu-Hyun Bae, Soo-Dong Park, Jae-Jung Shim and Jung-Lyoul Lee * \\ R \& BD Center, hy Co., Ltd., 22, Giheungdanji-ro 24beon-gil, Giheung-gu, Yongin-si 17086, Korea; \\ sta16000@hy.co.kr (S.-J.M.); yuyu03@hy.co.kr (B.N.); martin8899@hy.co.kr (C.-H.B.); soodpark@hy.co.kr (S.-D.P.); \\ jjshim@hy.co.kr (J.-J.S.) \\ * Correspondence: jlleesk@hy.co.kr; Tel.: +82-70-7835-5997
}

check for

updates

Citation: Mo, S.-J.; Nam, B.; Bae, C.-H.; Park, S.-D.; Shim, J.-J.; Lee, J.-L. Characterization of Novel

Lactobacillus paracasei HY7017 Capable of Improving Physiological Properties and Immune Enhancing Effects Using Red Ginseng Extract. Fermentation 2021, 7, 238. https://doi.org/ $10.3390 /$ fermentation7040238

Academic Editor: Armin Tarrah

Received: 27 August 2021

Accepted: 18 October 2021

Published: 21 October 2021

Publisher's Note: MDPI stays neutral with regard to jurisdictional claims in published maps and institutional affiliations.

Copyright: (c) 2021 by the authors. Licensee MDPI, Basel, Switzerland. This article is an open access article distributed under the terms and conditions of the Creative Commons Attribution (CC BY) license (https:// creativecommons.org/licenses/by/ $4.0 /)$.

\begin{abstract}
Red ginseng has powerful potential for use as a prebiotic, but its use is limited due to its antibacterial activity. The aim of this study is to present panax ginseng's endophytic lactic acid bacteria capable to overcome the antibacterial activity of red ginseng and improve their characteristic. Lactobacillus paracasei HY7017 (HY7017) was cultured in a medium supplemented with red ginseng. The probiotic properties and immune-enhancing effects of HY7017 were investigated in vitro and in vivo. HY7017 was proliferated strongly in RGE and had significantly improved properties compared with an L. paracasei type strain ATCC25302. HY7017 cultured in RGE-supplemented medium increased the production of nitric oxide, TNF- $\alpha$, and IL- 6 in macrophages, and increased IL-12 and IFN- $\gamma$ secretion in splenocytes. Furthermore, HY7017 restored WBC counts, increased the amount of IL-2 and IFN- $\gamma$ released, and enhanced the cytotoxicity of natural killer cells when orally administered to immunosuppressed mice. Moreover, HY7017 has properties that make it suitable as a probiotic, such as stability in the gastrointestinal tract and adhesion to Caco-2 cells. This study showed that HY7017 cultured with RGE may contribute to the development of probiotics to enhance immunity.
\end{abstract}

Keywords: immune; Lactobacillus paracasei; probiotics; red ginseng

\section{Introduction}

Red ginseng, which is the steamed root of ginseng that has been dried, is widely used as a therapeutic dietary herb for its medicinal anti-inflammatory, anti-cancer, and anti-diabetic effects [1-4]. Ginsenosides are a major component of red ginseng that exhibit pharmacological properties. These are converted to less polar and more bioavailable forms during the heating process involved in red ginseng production; Rh2 and Rg3 are examples of ginsenosides that are found only in red ginseng [5-7]. Ginseng also contains various constituents such as polysaccharides, peptides, fatty acids, and polyacetylenes [8,9]. Therefore, investigating the use of red ginseng as a culture medium for microorganisms is an active area of research.

Probiotics are defined as live microorganisms that have health benefits to the host when administered in adequate amounts. As well as providing the general benefit of favorably regulating gut microbial composition, probiotics can create a healthy gastrointestinal tract and immune system [10]. There is increasing interest in the health promoting function of foods [11]. Furthermore, among probiotics, lactic acid bacteria (LAB) and bifidobacteria are safe and widely used [12]. But the low viability and stability of probiotics mean that developing formulas in media other than dairy products is a challenge [13]. In addition, probiotics need to survive in sufficient numbers through the gastrointestinal tract and adhere to and colonize the gut to be beneficial to the host [14-16]. Therefore, the ability to survive acidic and bile conditions and colonize the intestinal mucosa are essential criteria for probiotic selection. The ability to meet these criteria, using appropriate technology, must be determined during the production of probiotics. 
In this study, we present a novel strain with enhanced beneficial effects of probiotics through the physiologically active components of red ginseng. We showed that supplementing Lactobacillus paracasei HY7017 culture medium with 3\% RGE improved the efficiency of the culture process, such as increasing bacterial numbers and the number of cells harvested. In addition, HY7017 cultured in media supplemented with RGE increased nitric oxide (NO) inducible nitric oxide synthase (iNOS), cyclooxygenase-2 (COX-2), tumor necrosis factor- $\alpha$ (TNF- $\alpha$ ), and interleukin-6 (IL-6) production in RAW 264.7 cells, and increased interferon- $\gamma($ IFN- $\gamma$ ) secretion from splenocytes. Furthermore, HY7017 enhanced the proliferation of splenocytes, restored white blood cell (WBC) levels, and increased secretion of interleukin-2 (IL-2), IFN- $\gamma$, and the cytotoxicity of natural killer (NK) cells when orally administered to immunosuppressed mice. Finally, supplementation with $3 \%$ RGE enhanced the probiotic properties of HY7017, such as gastrointestinal tract (GIT) tolerance and adhesion to Caco-2 cells.

\section{Materials and Methods}

\subsection{Characterization of HY7017}

2.1.1. Isolation and Identification of Endophytic LAB Strains

Ginseng (Panax ginseng C.A. Meyer.) roots were obtained at Punggi-eup field, Korea. Ginseng was stored at $4{ }^{\circ} \mathrm{C}$, and endophytes were isolated within $24 \mathrm{~h}$. The isolation of endophytic LABs from ginseng roots was performed using the previous method [17]. Briefly, the ginseng was thoroughly washed, cleaned of soil, and then the root surface was sterilized in $70 \%(v / v)$ ethanol for $1 \mathrm{~min}$ and was disinfected with $1 \%$ sodium hypochlorite for $10 \mathrm{~min}$. The epidermis of the ginseng root was removed with a sterile razor blade. The sample was pulverized with a grinder to obtain $10 \mathrm{~g}$ and then diluted with $90 \mathrm{~mL}$ sterile water. Next, the sample was serially diluted in $9 \mathrm{~mL}$ sterile diluent and smeared on de Man, Rogosa, and Sharpe (MRS; BD Biosciences, Franklin Lakes, NJ, USA) agar for $24-48 \mathrm{~h}$. After colonies that formed on the plate were separated, they were inoculated into 2 Brix RGE mixed with 5 Brix red ginseng extract and M9 minimal medium and incubated at $37^{\circ} \mathrm{C}$ for $48 \mathrm{~h}$. After incubation, OD600 values were measured with a microplate reader (BioTek, Winooski, VT, USA) at 24 and $48 \mathrm{~h}$. The colonies that produced the greatest increase in OD value were selected and re-blotted on a 2 Brix red ginseng agar plate; this strain was used for subsequent experiments. The strain was identified through 16S rRNA sequencing (Macrogen, Inc., Seoul, Korea) performed using universal rRNA gene primers (27F and 1492R). 16S rRNA sequencing results were compared with the Genbank database through the Basic Local Alignment Search Tool (BLAST) of the National Center for Biotechnology Institute (NCBI). The sequenced strain was named L. paracasei HY7017 and was deposited in Korea Collection for Type Cultures (KCTC, Jeongeup-si, Jeollabuk-do, Korea) with accession number KCTC14616BP. L. paracasei type strain ATCC25302 was purchased from the American Type Culture Collection (ATCC, Rockville, MD, USA).

2.1.2. Measurement of the Bacterial Number in Medium Supplemented with RGE during the Fermentation Process

To investigate the effect of RGE on the growth of microorganisms, $10 \mathrm{~mL}$ MRS broth was prepared containing either $1 \%, 3 \%, 5 \%$, or $10 \%$ RGE. Activated L. paracasei strains were inoculated with $1 \%(v / v)$ of each medium by serial passage twice in each medium, followed by anaerobic incubation at $37^{\circ} \mathrm{C}$ for $24 \mathrm{~h}$. To measure the number of LAB in each prepared medium, the collected sample was diluted according to the decimal dilution method using sterile physiological saline, and then cultured at $37^{\circ} \mathrm{C}$ in an agar medium for plate measurement containing bromocresol purple (BCP; Eiken Chemical, Tokyo, Japan). The resulting colonies were then measured.

To investigate the effect of 3\% RGE on the fermentation process in mass culture using a fermenter, MRS medium containing 3\% RGE was prepared. The $2 \mathrm{~L}$ MRS was inoculated with $1 \%(v / v)$ of the L. paracasei strains pre-cultured in medium containing $3 \%$ RGE and then fermented. The cells were harvested by centrifugation for $20 \mathrm{~min}$ to remove the 
culture solution; the final volume of harvested cells was $100 \mathrm{~mL}$. The harvested cells were homogenized; a freeze-drying protective agent was added; the cells were frozen at $-40{ }^{\circ} \mathrm{C}$; and then the cells were dried in a freeze dryer. The dried cells were pulverized and powdered. The culture solution, concentrated solution, and powder were each diluted in sterile physiological saline, spread on BCP medium, cultured at $35^{\circ} \mathrm{C}$ for $48 \mathrm{~h}$, and then the number of viable cells was measured.

\subsubsection{HPLC Measurement of Ginsenosides in HY7017}

To fractionate HY7017, a cellular fractionation process was performed. Briefly, HY7017 were washed three times to completely remove the culture medium. After centrifugation, the HY7017 pellet was diluted in $1 \mathrm{~mL}$ phosphate-buffered saline (PBS; Sigma-Aldrich, St. Louis, MO, USA) and then transferred to lysing matrix b (MP biomedicals, Irvine, CA, USA), disrupted with a FastPrep-24 Classic (MP biomedicals). Then the lysate was transferred to an EP tube (Eppendorf, Hamburg, Germany) and centrifugation at 13,200 rpm for $5 \mathrm{~min}$. the supernatant was referred cytosol fraction and the pellet was referred membrane fraction. The supernatant and pellet were collected through the cellular fractionation process and were transferred to an LC vial. The ginsenoside standards $\mathrm{Rb} 1$ and 20(S, R)-Rg3 were purchased from Sigma-Aldrich. The contents of the ginsenosides Rb1 and Rg3 were determined using an Agilent Technologies 1260 High-Performance Liquid Chromatography (HPLC) system coupled to a C18 column $\left(250 \times 4.5 \mathrm{~mm}, 6.0 \mu \mathrm{m}\right.$, Supelco ${ }^{\circledR}$, St. Louis, MO, USA). The mobile phase consisted of water (solvent A, 85\%) and acetonitrile (solvent B, $15 \%$ ) at $45^{\circ} \mathrm{C}$ at a flow rate of $1.6 \mathrm{~mL} / \mathrm{min}$.

\subsection{Assay for Immune Activity}

\subsubsection{Analysis of NO Production on RAW 264.7 Cells}

The murine macrophage cell line RAW 264.7 was obtained from the Korean Cell Line Bank (KCLB 40071). Cells were cultured in Dulbecco's modified Eagle's medium (DMEM; Gibco, Waltham, MA, USA) containing 10\% (v/v) fetal bovine serum (FBS; Gibco) and 1\% $(v / v)$ penicillin-streptomycin solution (Hyclone, Logan, UT, USA). The amount of nitrous oxide in the cell culture medium was determined using the previous method [18]. RAW 264.7 cells $\left(2 \times 10^{5}\right.$ cells / well) were plated in 96-well cell culture plates and incubated with $1 \mu \mathrm{g} / \mathrm{mL}$ lipopolysaccharide (LPS) and LAB strains $\left(10^{5} \mathrm{CFU} /\right.$ well $)$ for $24 \mathrm{~h}$. After incubation, $100 \mu \mathrm{L}$ cell culture medium was added to the same amount of Griess reagent (Sigma-Aldrich). The absorbance of the sample was measured at $540 \mathrm{~nm}$ using a microplate reader. NO production was calculated relative to sodium nitrate as a standard.

\subsubsection{Quantitative Reverse-Transcription Polymerase Chain Reaction Analysis}

RNA was isolated from cells using the TRIzol reagent (Invitrogen, Carlsbad, CA, USA). cDNA was synthesized from $2 \mu \mathrm{g}$ RNA on a thermal cycler (Bio-Rad, Hercules, CA, USA) using Maxime RT PreMix (iNtRON Biotechnology, Seongnam, Korea); the reaction ran for 60 min. The cDNA was analyzed by qPCR (Applied Biosystems, Carlsbad, CA, USA) using the TaqMan Probe-Based Gene Expression analysis system in combination with TaqMan Gene Expression Master Mix containing ROX (Applied Biosystems). Quantification of iNOS (Mm01309902_m1), COX-2 (Mm00478372_m1), IL-12 (Mm00434169_m1), IFN- $\gamma$ (Mm99999071_m1), and GAPDH (Mm99999915_g1) transcripts was performed using genespecific primers. Expression data were normalized against the corresponding level of GAPDH. To compare mRNA levels between groups, relative mRNA levels were calculated using the $2^{-\Delta \Delta C T}$ method.

\subsubsection{Determination of Cytokines by ELISA In Vitro}

To obtain splenocytes, spleens were removed from mice. The spleens were then gently pressed with a syringe and forced through a $70 \mu \mathrm{m}$ cell strainer (SPL Life Sciences, Pocheon-si, Gyeonggi-do, Korea). Cells were treated with RBC lysis buffer (Sigma-Aldrich, St. Louis, MO, USA), and isolated splenocytes were incubated in RPMI-1640 (Gibco) 
containing $10 \%$ FBS and $1 \%$ penicillin-streptomycin (Hyclone) in a $5 \% \mathrm{CO}_{2}$ incubator. For measurement of cytokine on RAW 264.7 cells and splenocytes, the cells were placed to a 6-well plate at $1 \times 10^{6}$ cells /well and incubated at $37{ }^{\circ} \mathrm{C}$ and $5 \% \mathrm{CO}_{2}$ for $48 \mathrm{~h}$. After incubation, the cells were treated with the samples for $24 \mathrm{~h}$; LPS $(1 \mu \mathrm{g} / \mathrm{mL}), 3 \%(v / v)$ RGE, LAB strains $\left(1 \times 10^{6} \mathrm{CFU} / \mathrm{mL}\right)$. The TNF- $\alpha$, IL- 6 , IL-10, IL-12, and IFN- $\gamma$ concentration in the culture medium was determined by ELISA kit (R\&D Systems, Minneapolis, MN, USA) according to the manufacturer's instructions.

\subsubsection{Analysis of Splenic NK Cell Activity}

NK cells were isolated from splenocytes using CD49b (DX5) MicroBeads (Miltenyi Biotec Technology, Bergisch Gladbach, Germany) according to the manufacturer's instructions. NK-cells $\left(1 \times 10^{5}\right.$ cells / well $)$ were co-cultured with YAC- 1 cells $\left(1 \times 10^{5}\right.$ cells /well $)$ at a ratio of $1: 1$ in a 96-well v-bottom plate. And the cells were treated with the samples for $24 \mathrm{~h}$; LPS $(1 \mu \mathrm{g} / \mathrm{mL}), 3 \%$ RGE $(1.5 \mathrm{mg} / \mathrm{mL}), \mathrm{LAB}$ strains $\left(1 \times 10^{5} \mathrm{CFU} /\right.$ well $)$. The cytotoxic effects of the obtained supernatant were measured using a CytoTox 96 non-radioactive cytotoxicity assay kit (Promega, Madison, WI, USA) according to the manufacturer's instructions.

\subsubsection{Animal Experiment}

Balb/c mice (male, 6 weeks old, 20-25 g) were purchased from dooyeol biotech (Seoul, Korea) and maintained at $20-22{ }^{\circ} \mathrm{C}, 40-60 \%$ relative humidity, and a $12 \mathrm{~h}$ light/dark cycle, and fed an autoclaved standard laboratory diet, and allowed free access to water. The experimental procedure was approved by the Ethics Review Committee of R\&D center, hy co., Ltd., Korea (AEC-2021-0003-Y). The protocol for immunosuppression mice model was performed according to a previous method [19]. An immunosuppression model was established by intraperitoneal (i.p.) injection of cyclophosphamide (CP, Sigma-Aldrich) in sterile saline $(150 \mathrm{mg} / \mathrm{kg})$ twice every second day in 35 mice. After 1 week of adaptation, mice were randomly divided into six groups ( $n=7$ per group) as follows: normal mice (NOR), CP alone (CP), CP plus beta-glucan positive control ( $\beta$-glucan, $20 \mathrm{mg} / \mathrm{kg}), \mathrm{CP}$ plus $1 \times 10^{9} \mathrm{CFU} / \mathrm{kg}$ HY7017 cultured in MRS (high-dose HY7017-M), CP plus $1 \times 10^{8} \mathrm{CFU} / \mathrm{kg}$ HY7017 cultured in MRS supplemented with 3\% RGE (low-dose HY7017-RGEs), and CP plus $1 \times 10^{9} \mathrm{CFU} / \mathrm{kg}$ HY7017 cultured in MRS supplemented with 3\% RGE (high-dose HY7017-RGEs. L. paracasei HY7017 was administered $24 \mathrm{~h}$ after the last injection of CP. The NOR and CP groups were administered distilled water via oral gavage.

\subsubsection{Analysis of Immune-Enhancing Effects in Immunosuppressed Mice}

Whole blood and spleen were collected at the end of the experiment. The spleen was weighed immediately after sacrifice, and splenocyte and NK cell isolation was performed as previously described. To evaluate splenocyte proliferation, splenocytes were placed into 96-well flat-bottomed microplates in triplicate at $5 \times 10^{5}$ cells /well, and then $4 \mu \mathrm{g} /$ well of ConA (T-cell mitogen) and $1 \mu \mathrm{g} /$ well of LPS (B-cell mitogen) were added to the wells. The cells were incubated in a total volume of $100 \mu \mathrm{L} /$ well. Serum-free RPMI 1640 medium was used as the control. The proliferated cells were counted using a CCK-8 assay kit (Dojindo Molecular Technologies, Kumamoto, Japan). Next, whole blood collected in heparinized tubes was analyzed for RBC and WBC counts. Total numbers of RBC and WBC were tested using an auto hematology analyzer (BC-5000Vet, mindray, Shēnzhèn, China). Next, the IL-2 and IFN- $\gamma$ concentration in the culture medium was determined by ELISA kit (R\&D Systems, Minneapolis, MN, USA) according to the manufacturer's instructions. Finally, the cytotoxic effects of the obtained supernatant were measured using a CytoTox 96 non-radioactive cytotoxicity assay kit (Promega, Madison, WI, USA) according to the manufacturer's instructions. 


\subsection{Probiotic Properties of HY7017}

\subsubsection{Resistance to the Effects of the GI Tract}

We evaluated the potential of HY7017 grown in a 3\% RGE-supplemented medium as a probiotic by measuring survival in physiological conditions similar to those of the human GIT [20]. To this end, in vitro digestion tests were performed to evaluate resistance to saliva, gastric juice, and bile salts. Simulated Salivary Fluid (SSF), simulated gastric fluid (SGF), and simulated intestinal fluid (SIF) were preheated to $37^{\circ} \mathrm{C}$ prior to in vitro digestion of bacteria. Then, $5 \mathrm{~mL}$ HY7017 or ATCC 25302 culture was poured into a $50 \mathrm{~mL}$ conical tube. The oral simulation was performed by adding $26 \mu \mathrm{L}$ of $0.3 \mathrm{M} \mathrm{CaCl}_{2}$ solution and $4 \mathrm{~mL}$ of $6.55 \mathrm{mg} / \mathrm{mL} \alpha$-amylase solution in SSF. The $\mathrm{pH}$ was then adjusted to 7.0 with $1 \mathrm{M} \mathrm{NaOH}$, and the mixture was incubated at $37^{\circ} \mathrm{C}$ for $2 \mathrm{~min}$. The gastric fluid simulation was performed by adding $6 \mu \mathrm{L}$ of $0.3 \mathrm{~mol} / \mathrm{L} \mathrm{CaCl}_{2}, 694 \mu \mathrm{L}$ distilled water, and $9.1 \mathrm{~mL}$ of $0.07 \mathrm{mg} / \mathrm{mL}$ pepsin to SGF. The $\mathrm{pH}$ was adjusted to 3 with $1 \mathrm{M} \mathrm{HCl}$, and the mixture was incubated at $37^{\circ} \mathrm{C}$ with continuous shaking for $2 \mathrm{~h}$. The intestinal phase was simulated by adding $40 \mu \mathrm{L}$ of $0.3 \mathrm{M} \mathrm{CaCl}_{2}, 1.31 \mathrm{~mL}$ distilled water, $2.5 \mathrm{~mL}$ of $160 \mathrm{mM}$ bile extract, and $16 \mathrm{~mL}$ of $22.15 \mathrm{mg} / \mathrm{mL}$ pancreatic solution. The $\mathrm{pH}$ was raised to 7.0 by adding $1 \mathrm{M}$ $\mathrm{NaOH}$, and the mixture was incubated at $37^{\circ} \mathrm{C}$ for $2 \mathrm{~h}$ with shaking. For each step, a control group cultured in PBS was set. At the end of each simulation, aliquots of HY7017 or ATCC25302 were collected, and viable cell counts were measured to determine the viability after simulated saliva, gastric fluid, and intestinal fluid digestions.

\subsubsection{Adhesion to Caco-2 Cells}

The rate of adhesion of HY7017 and ATCC25302 to human Caco-2 adenocarcinoma colon cells was measured as previously described [21]. Caco-2 cells were cultured in DMEM supplemented with $10 \%$ heat-inactivated FBS and 1\% antibiotic/antifungal solution at $37^{\circ} \mathrm{C}$ in an atmosphere containing $5 \% \mathrm{CO}_{2}$. Caco-2 cells were seeded at a concentration of $1 \times 10^{6}$ cells/well in 6-well plates. After the cells were grown to $100 \%$ confluence, the medium was replaced with DMEM without antibiotics and FBS. MRS or RGE-supplemented MRS-cultured HY7017 and ATCC25302 were diluted in PBS, and each well of CaCo-2 cells was inoculated with $1.0 \times 10^{9} \mathrm{CFU} / \mathrm{mL}$ HY7017 or ATCC25302 for $2 \mathrm{~h}$ at $37^{\circ} \mathrm{C}$ in $5 \% \mathrm{CO}_{2}$ to allow HY7017 or ATCC25302 to adhere to Caco-2 cells. Cells were then washed three times with PBS and treated with $0.025 \%$ trypsin-EDTA (Gibco) for $10 \mathrm{~min}$ to detach the cells from the plate. The isolated bacterial cells were serially diluted with PBS and plated on MRS agar medium. Plates were incubated at $37^{\circ} \mathrm{C}$ for $72 \mathrm{~h}$, and then the number of colonies was counted $\left(\mathrm{A}_{1}, \mathrm{CFU} / \mathrm{mL}\right)$. L. paracasei $\mathrm{HY} 7017$ or L. paracasei ATCC25302 added first to each well of the plate were also assayed $\left(\mathrm{A}_{0}, \mathrm{CFU} / \mathrm{mL}\right)$. The adhesion rate was calculated as follows.

$$
\% \text { Adhesion ability }=\left(A_{1} / A_{0}\right) \times 100
$$

\subsection{Statistical Analysis}

All data are expressed as mean standard error. Significant differences were statistically analyzed using one-way analysis of variance (ANOVA), followed by Tukey's multiple range test $(p<0.05)$. The obtained data were analyzed using GraphPad Prism 7 program (GraphPad Software, Inc, San Diego, CA, USA)

\section{Results}

\subsection{Characteristics of HY7017 in Response to RGE}

\subsubsection{Endophytic LABs Isolation and Identification}

Endophytic LABs were isolated from the ginseng root system; four strains increased the OD value in 2 Brix RGE, and the strain with the greatest increase in OD value was selected for further experiments. Through $16 \mathrm{~S}$ rRNA sequencing, the strain was confirmed as L. paracasei, and we named this strain HY7017. To confirm that the growth of HY7017 was dependent on the Brix of red ginseng, M9 minimal medium, 0.5 Brix, 1 Brix, 2 Brix, and 
5 Brix RGE were prepared. The number of viable cells increased in proportion to the Brix of RGE (Figure 1). In particular, HY7017 cultured in 5 Brix RGE produced $>10^{8} \mathrm{CFU} / \mathrm{mL}$ of bacteria. When the same experiment was performed using ATCC25302, the number of viable cells was not dependent on the concentration of RGE (Figure 1).

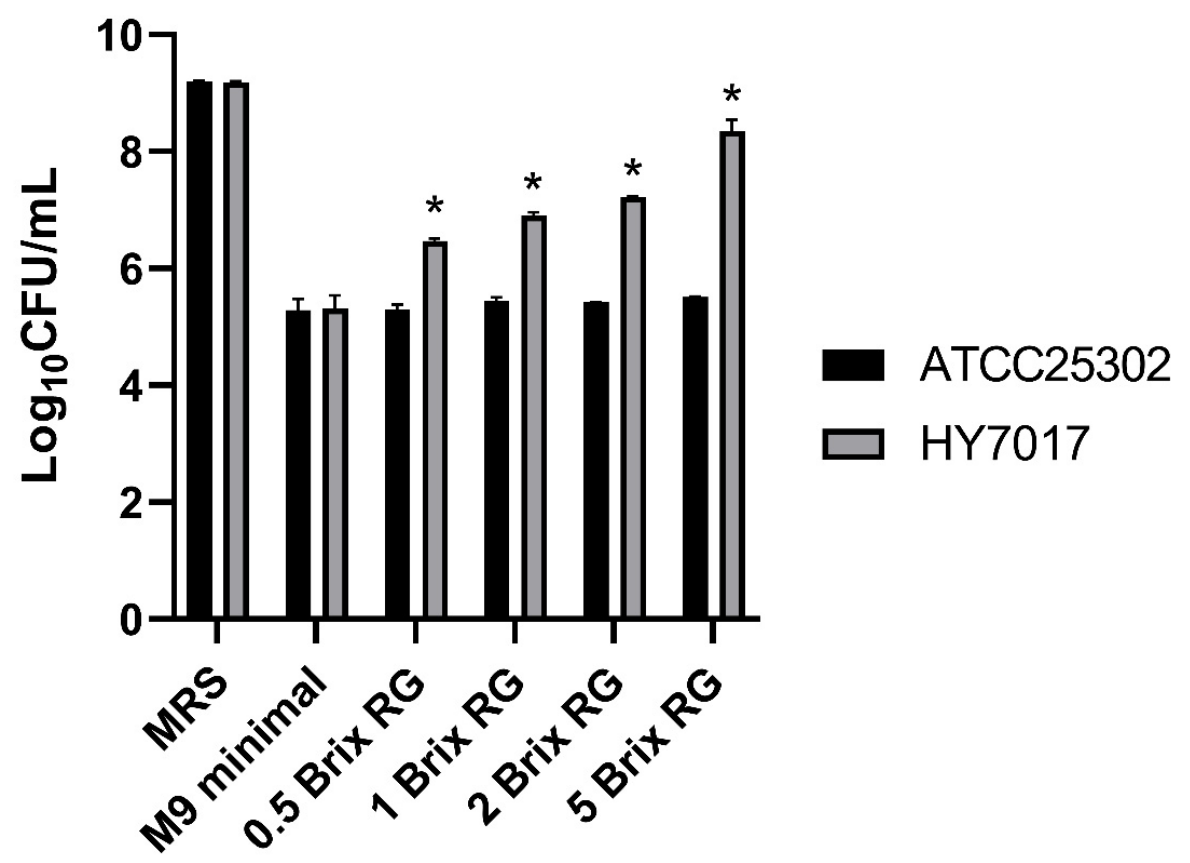

Figure 1. Bacterial numbers $\left(\log _{10} \mathrm{CFU} / \mathrm{mL}\right)$ of Lactobacillus paracasei strains grown in MRS, M9 minimal medium, 0.5 Brix RG, 1 Brix RG, 2 Brix RG, and 5 Brix RG. Data are represented as mean \pm standard error of the mean (SEM) of three independent experiments. ${ }^{*} p<0.05$, compared with M9 minimal. MRS, cultured in MRS broth; M9 minimal, cultured in M9 minimal medium; 0.5 Brix RG, cultured in 0.5 Brix RGE broth; 1 Brix RG, cultured in 1 Brix RGE broth; 2 Brix RG, cultured in 2 Brix RGE broth; 5 Brix RG, cultured in 5 Brix RGE broth.

\subsubsection{Growth Performance of HY7017 in RGE-Supplemented Medium}

To investigate the role of RGE as a cell culture supplement, we measured the number of viable cells of HY7017 and ATCC25302 for each RGE concentration added to the MRS broth (Table 1). The number of ATCC25302 cultured in MRS was $1.58 \times 10^{9} \mathrm{CFU} / \mathrm{mL}$, and the number of viable cells decreased as RGE was added. In 3\% RGE-supplemented medium, the number of viable cells was $2.67 \times 10^{8} \mathrm{CFU} / \mathrm{mL}$. The number of viable cells of HY7017 cultured in MRS was $1.54 \times 10^{9} \mathrm{CFU} / \mathrm{mL}$, and $2.08 \times 10^{9} \mathrm{CFU} / \mathrm{mL}$ in MRS supplemented with $3 \%$ RGE. The number of viable cells cultured in MRS supplemented with $1 \%, 5 \%$, and $10 \%$ RGE was similar.

Table 1. The bacterial number of Lactobacillus paracasei strains in MRS according to RGE content.

\begin{tabular}{ccc}
\hline Strain & Red Ginseng Extract (\%) & Bacterial Number (CFU/mL) \\
\hline L. paracasei ATCC25302 & 0 & $1.58 \times 10^{9} \pm 0.07$ \\
& 1 & $1.23 \times 10^{9} \pm 0.15$ \\
& 3 & $2.67 \times 10^{8} \pm 0.35^{* *}$ \\
L. paracasei HY7017 & 5 & $2.13 \times 10^{8} \pm 0.15^{* *}$ \\
& 10 & $2.07 \times 10^{8} \pm 0.12 * *$ \\
\hline
\end{tabular}

The data are presented as the mean \pm SEM. ${ }^{*} p<0.05,{ }^{* *} p<0.01$ vs. $0 \%$ group. 
We performed mass culture using a fermenter to determine the effect of $3 \%$ RGE supplementation on the probiotic manufacturing process (Table 2). The number of viable cells inoculated into each culture condition was performed under the same conditions. The number of HY7017 bacteria cultured in MRS supplemented with 3\% RGE was slightly higher than that in MRS. The number of bacterial cells was dependent upon the culture conditions. The number of harvested cells from the normal medium was $9.73 \times 10^{10} \mathrm{CFU} / \mathrm{mL}$, whereas $2.11 \times 10^{11} \mathrm{CFU} / \mathrm{mL}$ cells were harvested from 3\% RGE-supplemented medium. The number of lyophilized cells was $3.57 \times 10^{11} \mathrm{CFU} / \mathrm{mL}$ in $3 \%$ RGE-supplemented medium, and $1.8 \times 10 \times 10^{11} \mathrm{CFU} / \mathrm{mL}$ in normal medium. The number of ATCC25302 viable cells in $3 \%$ RGE-supplemented medium was lower than in the normal medium at each step of the manufacturing process.

Table 2. Bacterial counts of Lactobacillus paracasei strains during the manufacturing process according to growth conditions.

\begin{tabular}{cccccc}
\hline \multirow{2}{*}{ Strain } & \multirow{2}{*}{ Growth Condition } & \multicolumn{4}{c}{ Manufacturing process (CFU/mL) } \\
\cline { 3 - 6 } & & Inoculation & Fermentation & Concentration & Lyophilization \\
\cline { 3 - 6 } L. paracasei & MRS & $4.67 \times 10^{9} \pm 0.55$ & $1.31 \times 10^{10} \pm 0.31$ & $2.15 \times 10^{11} \pm 0.95$ & $3.47 \times 10^{11} \pm 0.51$ \\
ATCC25302 & $+3 \%$ RGE & $4.67 \times 10^{9} \pm 0.55$ & $8.73 \times 10^{9} \pm 0.54$ & $1.33 \times 10^{11} \pm 0.49^{*}$ & $1.93 \times 10^{11} \pm 0.9^{*}$ \\
\hline \multirow{2}{*}{ L. paracasei HY7017 } & MRS & $5.03 \times 10^{9} \pm 0.35$ & $1.50 \times 10^{10} \pm 0.18$ & $9.73 \times 10^{10} \pm 0.64$ & $1.80 \times 10^{11} \pm 0.47$ \\
& $+3 \%$ RGE & $5.03 \times 10^{9} \pm 0.35$ & $1.74 \times 10^{10} \pm 0.13$ & $2.11 \times 10^{11} \pm 0.11^{*}$ & $3.57 \times 10^{11} \pm 0.4^{*}$ \\
\hline
\end{tabular}

The data are presented as the mean \pm SEM. ${ }^{*} p<0.05$ vs. Growth condition in MRS.

\subsubsection{Analysis of the Ginsenoside Content in HY7017}

We investigated the ability of HY7017 cultured in RGE-supplemented medium to accumulate ginsenosides in the cytoplasm. We measured the protopanaxadiol (PPD)-type ginsenoside Rb1 and Rg3. We showed that HY7017 takes up ginsenoside (Figure S1) by comparing the area of the peak representing Rb1 and Rg1 in the washing buffer and HY7017 lysate. The content of $\mathrm{Rb} 1$ in the culture medium increased according to the concentration supplemented with RGE, whereas Rb1 was reduced in the culture supernatant obtained after culturing HY7017 compared to the culture medium. Rg3 showed a tendency to slightly increase in the culture supernatant obtained after incubation of HY7017. There was no peak present in the washing solution, whereas a peak representing RGE was present in the HY7017 lysate, which was transformed by the enzyme activity of the LAB. The ginsenoside peak was not observed in the cytoplasmic fraction of HY7017 cultured in medium supplemented with $1 \%$ RGE. On the other hand, it was confirmed that Rg3 was uptake in HY7017 cytoplasm in RGE-supplemented medium of $2 \%$ or more. These results showed that $\mathrm{Rb} 1$ was converted to the minor ginsenoside $\mathrm{Rg} 3$ by hydrolysis of the sugar moiety by HY7017.

\subsection{The Immune-Enhancing Effect of HY7017}

\subsubsection{HY7017-Mediated Production of NO and Cytokines in RAW 264.7 Cells}

We investigated the immune-enhancing effect of heat-killed HY7017 and ATCC25302 treatment on RAW 264.7 cells (Figure 2). First, we showed the effect of heat-killed HY7017 treatment on NO production in RAW 264.7 cells (Figure 2A). NO release levels increased to $20.54 \pm 0.13 \mu \mathrm{M}$ in the LPS-treated group (LPS), but rather decreased in the $3 \%$ RGEtreated group. ATCC25302 did not affect the NO release level regardless of the RGE supplementation condition. By contrast, HY7017 cultured in 3\% RGE-supplemented medium (HY7017-RGEs) significantly increased NO release levels, but HY7017 cultured in MRS (HY7017-M) did not increase the NO level. Cells treated with HY7017-RGEs released $8.45 \pm 0.33 \mu \mathrm{M} \mathrm{NO}$, which was higher than the amount released by HY7017-M treated cells $(4.96 \pm 0.32 \mu \mathrm{M}$ NO). Next, we compared the levels of mRNAs encoding iNOS and COX-2 between cells treated with L. paracasei strains cultured in MRS and cells treated with $L$. paracasei strains cultured in medium supplemented with RGE. As shown in Figure 2B,C, the mRNA level of iNOS and COX-2 were significantly increased compared to the NT group, following treatment with HY7017-RGEs. It was observed that HY7017-RGEs 
significantly increased compared to HY7017-M at the mRNA level of iNOS, respectively. Finally, we conducted an ELISA to measure the amount of TNF- $\alpha$, IL-6, and IL-10 secreted from macrophages treated with LABs (Figure 2D-F). TNF $\alpha$ and IL-6 in RAW 264.7 cells increased by HY7017 treatment, but IL-10 was no significant difference. In particular, supplementing the medium with RGE could dramatically increase the secretion of TNF$\alpha$. While, ATCC25302 treatment significantly increased TNF- $\alpha$, but had no effect on the secretion of cytokines IL-6 and IL-10. These results indicate that HY7017-RGEs increase the release of pro-inflammatory cytokines but not anti-inflammatory cytokines.

A

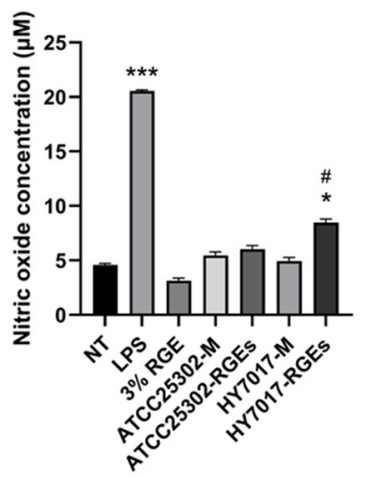

D

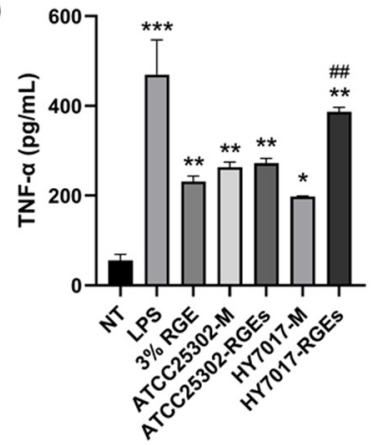

B

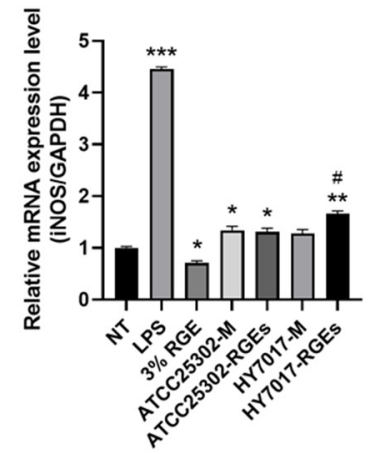

E

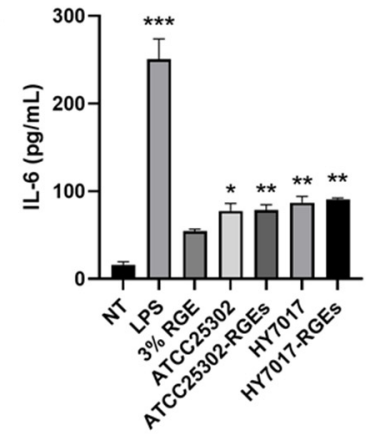

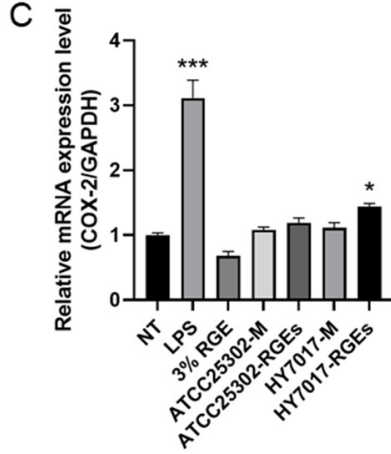

F

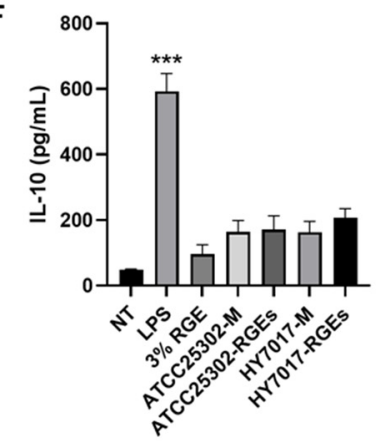

Figure 2. Effect of Lactobacillus paracasei HY7017 and ATCC25302 cultured in each medium on RAW 264.7 cells. The production of nitric oxide (NO) was measured by Griess reagent (A). Relative mRNA levels of iNOS (B) and COX-2 (C) were monitored by qPCR and normalized against GAPDH. The secretion of TNF- $\alpha$ (D), IL-6 (E) and IL-10 (F) were determined using an ELISA kit. Data are represented as mean \pm standard error of the mean (SEM) of three independent experiments. ${ }^{*} p<0.05$, ** $p<0.01$ and ${ }^{* * *} p<0.001$ compared with NT. \# $p<0.05$ and \#\# $p<0.01$ compared with HY7017-M. NT, non-treated group; LPS, treated with LPS; 3\% RGE, treated with 3\% RGE in PBS; ATCC25302$\mathrm{M}$, treated with $1 \times 10^{6} \mathrm{CFU} / \mathrm{mL}$ of ATCC25302 grown in MRS; ATCC25302-RGEs, treated with $1 \times 10^{6} \mathrm{CFU} / \mathrm{mL}$ of ATCC25302 grown in 3\% RGE-supplemented MRS; HY7017-M, treated with $1 \times 10^{6} \mathrm{CFU} / \mathrm{mL}$ of HY7017 grown in MRS; HY7017-RGEs, treated with $1 \times 10^{6} \mathrm{CFU} / \mathrm{mL}$ of HY7017 grown in 3\% RGE-supplemented MRS.

\subsubsection{HY7017-Mediated Cytokine Production and NK Cell Activity in Splenocytes}

To investigate the immune-enhancing effect of LAB treatment, we isolated splenocytes and NK cells from spleens extracted from BALB/c mice and treated each cell type with heatkilled HY7017 and ATCC25302 (Figure 3). Figure 3A,B shows that HY7017-RGEs treatment significantly increased the mRNA levels of IL-12 and IFN- $\gamma$ in splenocytes. However, ATCC25302 treatment did not increase mRNA levels of IL-12 and IFN- $\gamma$. Likewise, IL-12 and IFN- $\gamma$ production was significantly increased in the HY7017-RGEs treatment, similar to the result of the mRNA level (Figure 3C,D). In particular, HY7017-RGEs treatment significantly increased IFN- $\gamma$ production than HY7017-M treatment. Finally, we confirmed the cytotoxicity of NK cells to YAC-1 cells (Figure 3E). The cytotoxicity of NK cells was $4.4 \%$ in NT-treated cells; $11.8 \%$ in LPS-treated cells; $6.6 \%$ in $3 \%$ RGE-treated cells; $7.2 \%$ in 
ATCC25302-M treated cells; 7.8\% in ATCC25302-RGEs treated cells; 8.4\% in HY7017-M treated cells, and 10.8\% in HY7017-RGEs treated cells. This result indicates that HY7017 cultured in 3\% RGE-supplemented medium most increases NK cell activity.

A

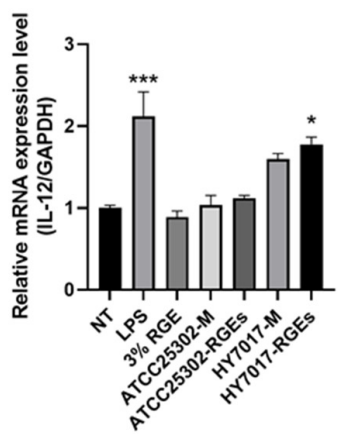

C

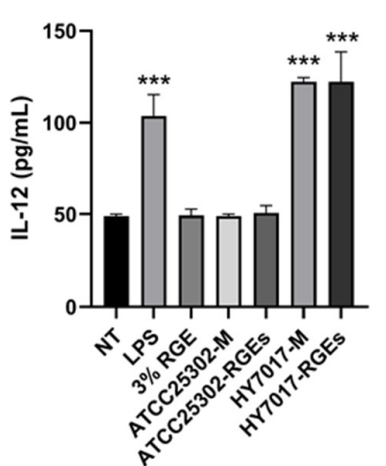

$\mathrm{B}$

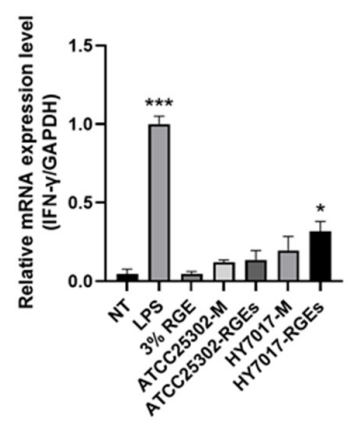

D

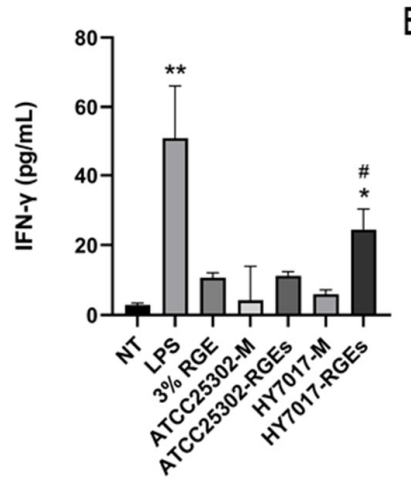

E

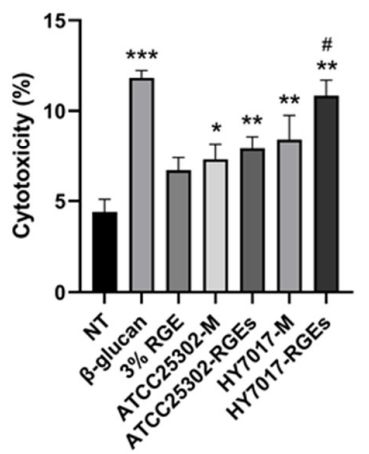

Figure 3. Effect of Lactobacillus paracasei HY7017 and ATCC25302 cultured in each medium on splenocytes. Relative mRNA levels of IL-12 (A) and IFN- $\gamma$ (B) were monitored by qPCR and normalized against GAPDH. The secretion of IL-12 (C) and IFN- $\gamma$ (D) were measured by ELISA kit. The splenic NK cell cytotoxicity (E) to YAC-1 was measured by CytoTox 96 non-radioactive cytotoxicity assay kit. Data are represented as the mean \pm standard error of the mean (SEM) of three independent experiments. ${ }^{*} p<0.05,{ }^{* *} p<0.01$ and ${ }^{* * *} p<0.001$ compared with NT. $\# p<0.05$ compared with HY7017-M. NT, non-treated group; LPS, treated with LPS; $3 \%$ RGE, treated with $3 \%$ RGE in PBS; ATCC25302-M, treated with $1 \times 10^{6} \mathrm{CFU} / \mathrm{mL}$ of ATCC25302 grown in MRS; ATCC25302-RGEs, treated with $1 \times 10^{6} \mathrm{CFU} / \mathrm{mL}$ of ATCC25302 grown in 3\% RGE-supplemented MRS; HY7017-M, treated with $1 \times 10^{6} \mathrm{CFU} / \mathrm{mL}$ of HY7017 grown in MRS; HY7017-RGEs, treated with $1 \times 10^{6} \mathrm{CFU} / \mathrm{mL}$ of HY7017 grown in 3\% RGE-supplemented MRS.

\subsubsection{Effect of Bacterial Fractions}

HY7017 cultured in MRS or 3\% RGE supplemented MRS were obtained to cell fractions. The membrane-rich pellet is referred to as the "membrane fraction", and the supernatant containing the soluble material is referred to as the "cytosol fraction". Our results showed that splenocytes treated with total lysate or cytosol fraction had significantly higher IFN- $\gamma$ levels than the non-treated group (Figure S2A). The increase in IFN- $\gamma$ levels in splenocytes treated with the membrane fraction was not significant. In addition, we showed that NK activity varied according to the fraction that the cells were treated with. The activity of NK cells treated with total lysate or cytosol fraction was significantly higher than in the non-treated group (Figure S2B). The activity of NK cells treated with the membrane fraction tended to be higher but was not significant.

\subsubsection{The Effect of Oral Administration of HY7017 to Immunosuppressed Mice}

To evaluate the immune-enhancing effect of HY7017 in vivo, HY7017 was administered to $\mathrm{CP}$-induced immunosuppressed mice. The spleen weight and splenocyte proliferative capacity, peripheral RBC and WBC counts, cytokine release from splenocytes, and NK activity were measured (Figure 4). We measured the effect of oral administration of HY7017 
for 5 days. CP treatment significantly reduced the weight of the mice by $57.94 \%$ compared with the normal group (Figure 4A). Oral administration of high-dose HY7017-RGEs slightly increased the weight of the spleen, but this effect was not significant.

A

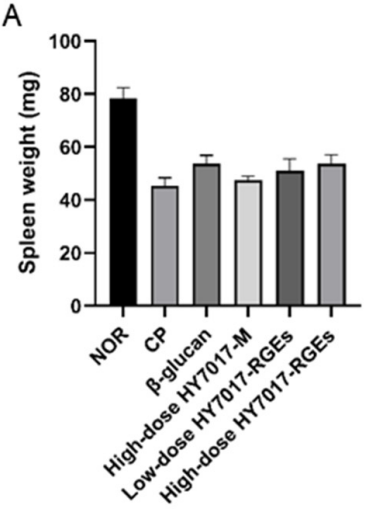

D
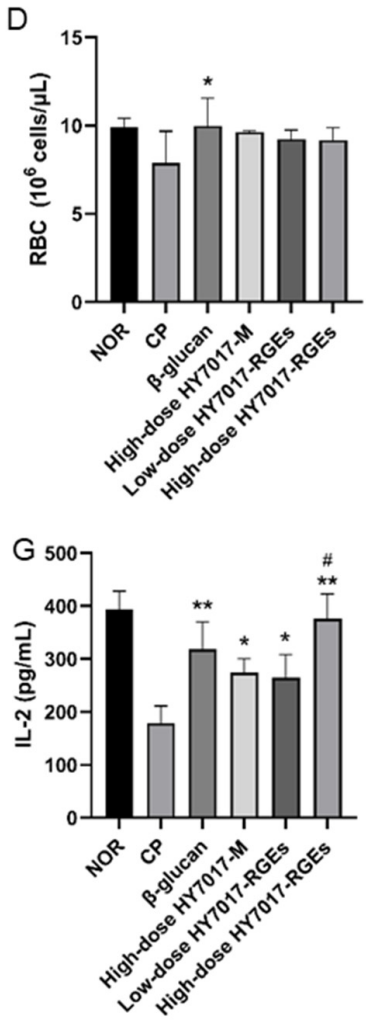

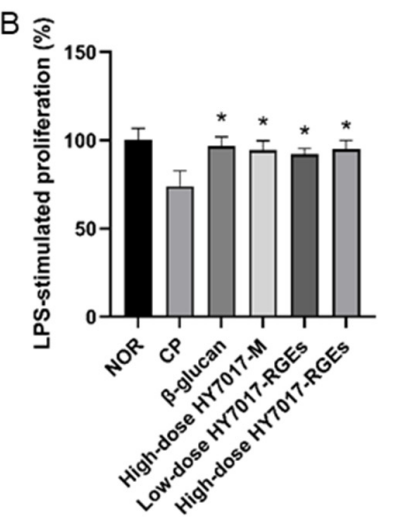

E

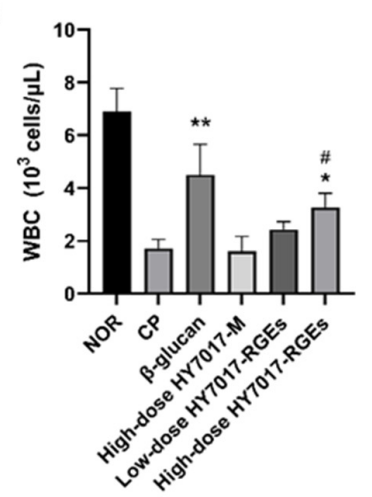

$\mathrm{H}$

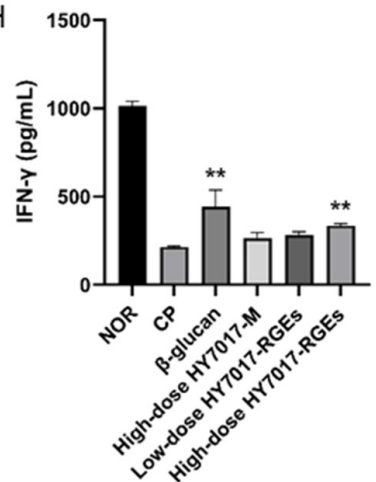

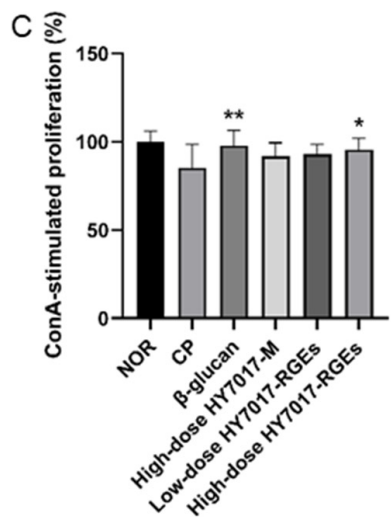

F
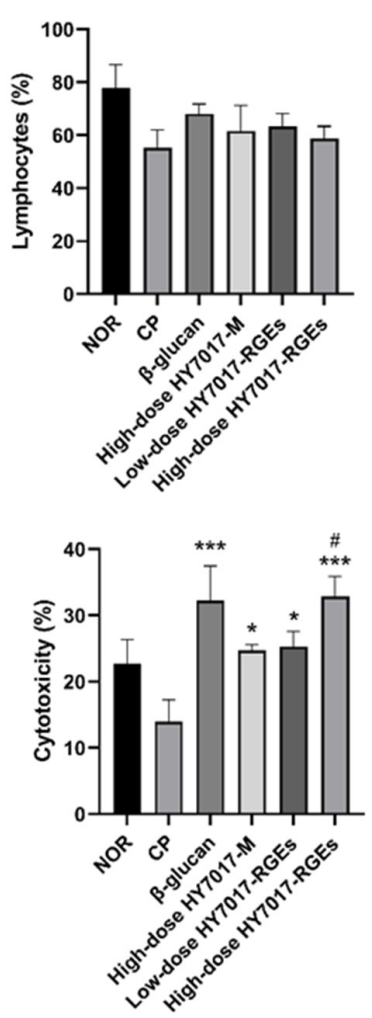

Figure 4. Effect of orally administered Lactobacillus paracasei HY7017 in CP-immunosuppressed mice on the weight of spleen (A), lipopolysaccharide-induced B-cell proliferation (B), and concanavalin A-induced T-cell proliferation lipopolysaccharide-induced B-cell proliferation $(\mathbf{C})$ in splenocytes. The number of red blood cells (RBC, $\left.\times 10^{6} / \mu \mathrm{L}\right)(\mathrm{D})$ and white blood cells $\left(\mathrm{WBC}, \times 10^{3} / \mu \mathrm{L}\right)(\mathrm{E})$; ratio of lymphocytes $(\mathbf{F})$; level of IL-2 (G) and IFN- $\gamma$ cytokines $(\mathbf{H})$ secreted from ConA-treated splenic cytotoxic T-cells; splenic NK cell activity (I). Data are represented as the mean \pm standard error of the mean (SEM) ( $n=7$ mice per group). ${ }^{*} p<0.05,{ }^{* *} p<0.01$ and ${ }^{* * *} p<0.001$ compared with CP. \# $p<0.05$ compared with High-dose HY7017-M. NOR, normal mice; CP, treated with CP; $\beta$-glucan, oral administration with $20 \mathrm{mg} / \mathrm{kg}$ of $\beta$-glucan for 5 days after $\mathrm{CP}$-induction; highdose HY7017-M, oral administration with $1 \times 10^{9} \mathrm{CFU} / \mathrm{mL}$ of HY7017 grown in MRS for 5 days after CP-induction; low-dose HY7017-RGEs, oral administration with $1 \times 10^{8} \mathrm{CFU} / \mathrm{mL}$ of HY7017 grown in 3\%RGE-supplemented MRS for 5 days after CP-induction; High-dose HY7017-RGEs, oral administration with $1 \times 10^{9} \mathrm{CFU} / \mathrm{mL}$ of HY7017 grown in 3\% RGE-supplemented MRS for 5 days after $\mathrm{CP}$ induction. 
We measured the effect of HY7017 on the proliferative capacity of splenocytes from CP-immunosuppressed mice stimulated with LPS and ConA (Figure 4B,C). CP treatment significantly reduced the proliferative response of lymphocytes to LPS and ConA to $86.4 \%$ and $85.1 \%$ of the normal group, respectively, at day 5 in CP-treated mice. Oral administration of high-dose HY7017-RGEs increased LPS-induced B-cell proliferation and ConA-induced T-cell proliferation to $94.9 \%$ and $95.52 \%$ of the normal group, respectively.

On day 5 after CP treatment, RBC and WBC levels were reduced to $81 \%$ and $30.4 \%$ respectively, compared with the normal group (Figure $4 \mathrm{D}-\mathrm{F}$ ); oral administration of highdose HY7017-RGEs for 5 days restored the level of and WBCs. However, the RBC level and lymphocyte ratio were not significantly different from the CP-treated group.

Next, we measured the effect of HY7017 on the expression of the immunoregulatory cytokines IL-2 and IFN- $\gamma$ in splenocytes isolated from CP-treated mice (Figure 4G,H). $\mathrm{CP}$ treatment significantly reduced the secretion of IL- 2 and IFN- $\gamma$ to $55.5 \%$ and $21.6 \%$, respectively, of normal splenocytes; Oral administration of HY7017-RGEs of CP-treated mice reversed the reductions in IL-2 and IFN- $\gamma$ secretion to $90.57 \%$ and $27.95 \%$ of normal splenocytes, respectively.

We orally administered HY7017 to CP-treated mice, isolated NK cells from the spleen, and measured the cytotoxic effects of the isolated cells on YAC-1 cells (Figure 4I). Treatment with CP alone significantly reduced the cytotoxic effects of NK cells compared with cells isolated from normal mice. Oral administration of high-dose HY7017-RGEs restored the cytotoxic effects of spleen-derived NK on YAC-1 cells.

\subsection{Probiotic Properties}

\subsubsection{Stability in the Gastrointestinal Tract}

To determine the stability of HY7017 and ATCC25302 in the GIT, HY7017, and ATCC25302 were cultured in MRS or 3\% RGE-supplemented MRS and tested in a simulated GIT model (Figure 5A). Our results showed that $88 \%$ of HY7017 cultured in MRS survived the oral stage, whereas 97\% of HY7017 cultured in 3\% RGE-supplemented MRS survived the oral stage. In the gastric simulation test, $68 \%$ of HY7017 cultured in MRS and $83 \%$ of HY7017 cultured in 3\% RGE-supplemented MRS survived gastric simulation. In the intestinal stage, $48 \%$ of HY7017 cultured in MRS survived the small intestine stage, whereas $65 \%$ of HY7017 cultured in 3\% RGE-supplemented MRS survived the small intestine stage. But we showed that there was no significant difference in the stability of ATCC25302 strains cultured in the RGE-containing medium or normal medium in the GIT. Overall, these results indicate that HY7017 grown in 3\% RGE-supplemented MRS has better GIT stability than the ATCC25302.
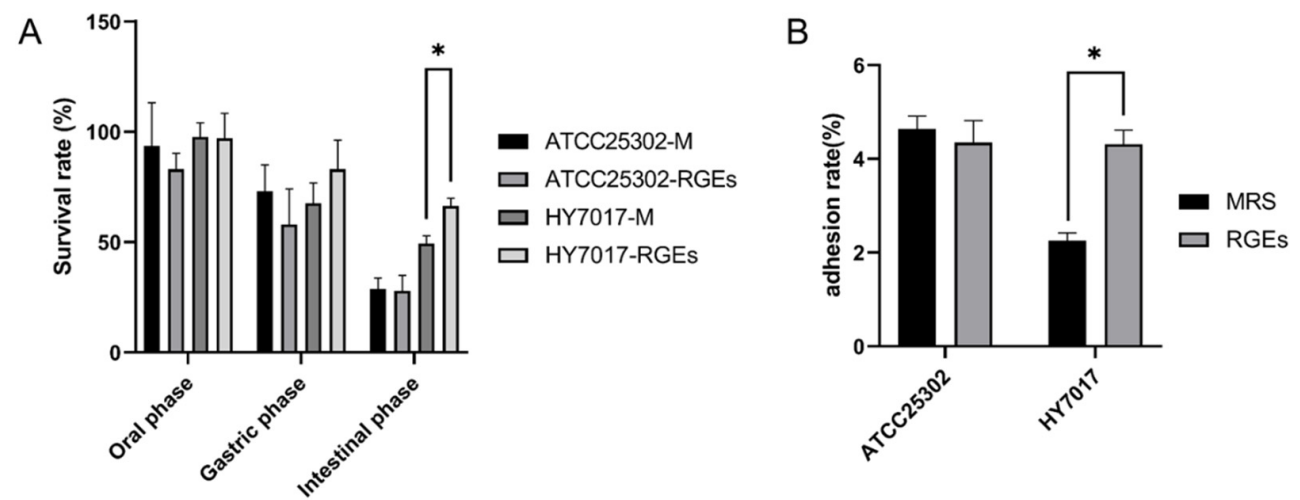

Figure 5. The survival rate of HY7017 and ATCC25302 during simulated gastrointestinal tract (A). The number of LAB attached to one Caco-2 cell under co-culture conditions (B). Data are represented as the mean \pm standard error of the mean (SEM) of three independent experiments $\left({ }^{*} p<0.05\right)$. 


\subsubsection{Adhesion Rate}

To determine the adhesion rate of caco-2 cells of HY7017 and ATCC25302, HY7017 and ATCC25302 were cultured in MRS or 3\% RGE-supplemented MRS (Figure 5B). HY7017 cultured in MRS had an adhesion rate of 2.1\%, and HY7017 cultured in 3\% RGE-supplemented MRS had an intestinal adhesion rate of $4.1 \%$. This result showed that HY7017 cultured in RGE had better intestinal adhesion. The intestinal adhesion rate of ATCC25302 cultured in MRS medium was $4.6 \%$, and the intestinal adhesion rate of ATCC25302 cultured in 3\% RGE-supplemented MRS had an intestinal adhesion rate of $4.3 \%$, demonstrating that the growth medium did not affect the intestinal adhesion of ATCC 25302.

\section{Discussion}

The aim of this study was to isolate potential probiotic strains of bacteria from ginseng root and was to compare the characteristics of these strains grown in culture media supplemented with RGE. There is a need to find LABs that have the ability to overcome the antibacterial activity of red ginseng [22] and to determine the optimal concentration of red ginseng extract that promotes probiotic bacterial growth. We isolated endophytic LABs from the ginseng roots and investigated the survival rate in RGE broth. 5 Brix RGE was diluted in M9 minimal medium to prepare 2 Brix RGE broth, and LAB having the highest OD value was selected when cultured in RGE broth. In addition, L. paracasei type strain ATCC25302 and HY7017 were cultured according to the concentration gradient of RGE. We observed that ATCC25302 could not grow in RGE, yet HY7017 produced more than $10^{8}$ viable cells in 5 Brix RGE. These results suggest that the growth-promoting characteristics of RGE are unique to HY7017. However, since there is a clear limitation of using RGE alone as a culture medium, an experiment was conducted to determine the role of growth media supplemented with RGE.

We examined the growth characteristics of ATCC25302 and HY7017 grown in RGEsupplemented medium. In medium supplemented with $0 \%, 1 \%, 3 \%, 5 \%$, and $10 \%$ RGE, growth of ATCC25302 was not promoted and was decreased at $3 \%$ or more RGE (Table 1). However, 3\% RGE promoted the growth of HY7017, and growth was not reduced at any of the RGE concentrations tested. These results are consistent with a report showing that saponin, a pharmacological component of red ginseng, promotes the growth of LAB at certain concentrations but inhibits growth above these concentrations [23]. The suppression of the growth of microorganisms with increasing RGE concentrations is thought to be due to the gradual increase in the antimicrobial molecules from red ginseng [22]. Therefore, concentrations of RGE supplements need to be optimized because the conditions for promoting growth are different for each species of bacteria. We compared how 3\% RGEsupplemented medium affected the growth of ATCC25302 and HY7017 in a mass-culture fermenter (Table 2). The growth performance of HY7017 cultured in 3\% RGE-supplemented MRS was 2-fold higher than HY7017 cultured in MRS. Increasing the efficiency of the LAB culture process can minimize the loss of cell harvest in the subsequent downstream process, resulting in increased productivity of probiotic production. Exopolysaccharide (EPS), a biogenic product of $\mathrm{LAB}$, forms a capsule around the cell wall that forms part of the cell wall or is present in a viscous form outside the cell wall [24]. EPS is a microbial polysaccharide that accumulates during fermentation and makes it difficult to harvest cells from the culture medium. Supplementation of culture medium with RGE seems to be related to the production of EPS. The exact mechanism that underlies the relationship between RGE and EPS has not been elucidated; it will be necessary to investigate in future studies whether the addition of RGE lowers biogenic products such as EPS, or whether RGE components interact with EPS. Overall, our results suggest that the supplementation of HY7017 growth media with RGE will be advantageous in the industrial production of HY7017 probiotics.

LAB has been validated through many studies as a safe microorganism that repair the disturbance of the gut microbiota [25] and induces non-specific activation of the host immune system [26]. For instance, L. acidophilus LAFTI L10 or L. paracasei LAFTI L26 
were able to enhance specific gut and systemic immune responses in mice by enhancing the secretion of anti-inflammatory cytokine IL-10 and pro-inflammatory cytokine IFN$\gamma$ [27]. Another study showed that all of the hydrolysates and whole cells from L. paracasei NTU101 induce the proliferation of macrophages and splenocytes and promote the release of IL-10 and IL-12 cytokines to modulate the innate and adaptive immune systems and inflammatory responses [28]. Previous work by our group showed that L. plantarum HY7712 significantly increased IL-2 and IFN- $\gamma$ production and NK cell activity in CPtreated mice [19]. However, studies on LAB improved the immune-enhancing effects have not been performed thoroughly. Therefore, to search LAB capable of improving immune-enhancing effects using RGE, we investigated first the ability of HY7017 isolated from ginseng roots to activate immune cells and then its immune-enhancing effect in immunosuppressed mice.

Macrophages are representative phagocytic cells involved in innate immunity that induce immune responses by directly phagocytosing pathogens or by secreting immune mediators such as cytokines [29]. Activated macrophages secrete NO, which acts as an immune signal transmitter, and NO activates other immune cells to increase resistance to pathogens [30]. NO is synthesized by iNOS, which is activated for the immune response [31], and NO activates COX-2 to produce PGE2 for the immune response [32]. In addition, activated macrophages promote the immune response by increasing the expression of cytokines such as TNF- $\alpha$, IL-6, and IL-10, which are considered important factors of the innate immune response. According to our data, treatment of HY7017 cultured in 3\% RGE supplemented medium increased NO production by raising the mRNA expression level of iNOS and increased secretion of pro-inflammatory cytokines such as TNF- $\alpha$ and IL-6. However, HY7017 treatment did not affect the secretion of the anti-inflammatory cytokine IL-10. These results indicated that HY7017 only exhibited an immune-enhancing effect and did not cause an inflammatory response.

Various immune cells such as T-cells, B-cells, macrophages, and NK cells exist in the splenocytes isolated from the spleen, and the culture supernatant contains a large number of cytokines secreted by these immune cells. IL-12 is a cytokine released from antigenpresenting cells that acts on naïve $\mathrm{T}$ cells to promote differentiation into Th1 cells [33] and follicular helper T precursor cells [34]. IFN- $\gamma$ can mediate cellular immune function and promote differentiation and proliferation of Th1 cells [35]. Since IFN- $\gamma$ is mainly produced in NK-cells and T-cells, it is a representative indicator of NK-cell and T-cell function [36]. Therefore, an increase in the expression level of IFN- $\gamma$ suggests that the activity of NK-cells and T-cells has increased, resulting in immune enhancement. NK-cells, which are the main type of cells responsible for innate immunity, are activated by IFN or macrophage-derived cytokines, and the activated NK-cells secrete cytokines such as IFN- $\gamma$ and TNF- $\alpha$ to promote apoptosis of stem cells or contribute to activating other immune cells $[37,38]$. As our data show, HY7017-RGEs raised production of IL-12 and IFN- $\gamma$, which are upregulated by the mRNA levels of IL-12 and IFN- $\gamma$, and significantly increased the NK cell activity. By contrast, ATCC25302 did not increase cytokine production and NK cell activity. In summary, HY7017 cultured in 3\% RGE-supplemented medium improved the immune-enhancing effect than HY7017 cultured in MRS.

The spleen, a major lymphoid organ where B-lymphocytes and T-lymphocytes mature, provides a protective immune response to antigens [39]. Thus, the size of the spleen and proliferation of spleen cells are important indicators of a functioning immune system [40]. In addition, WBCs play an important role in the body's defense system, swallowing foreign substances and producing antibodies [41]. The number of lymphocytes changes are used in part to diagnose immunosuppressive diseases and acute infectious diseases [42]. Furthermore, IL-2 is an important immunomodulatory that induces the differentiation of lymphoid cells and stimulates IFN- $\gamma$ production [43]. In this study, the oral administration of HY7017 cultured in 3\% RGE-supplemented medium tended to recover spleen size in immunosuppressed mice, but this effect was not significant (Figure 4A). Next, the proliferative ability of splenocytes was significantly increased following oral administration of high-dose HY7017 
grown in 3\% RGE-supplemented medium (Figure 4B,C). Next, the results of our study showed that high-dose HY7017 grown in 3\% RGE-supplemented medium restored CPinduced decreases in WBC levels, and the immunity of mice was improved (Figure 4D-F). Finally, oral administration of high-dose HY7017 grown in 3\% RGE-supplemented medium increased IL-2 and IFN- $\gamma$ production in splenocytes from immunosuppressed mice and restored NK cell activity in immunosuppressed mice (Figure 4G-I). Therefore, culturing HY7017 in the presence of RGE is advantageous for immune-enhancing effects in CP-induced mice.

In a previous study, it was reported that $L$. paracasei have immunomodulatory abilities via increased Th1-associated cytokines and reduced Th2-associated cytokines, switching the immune response from a Th2 toward a Th1 response. For example, L. paracasei V0151 IL-2, IL-4, IL-5, and IL-13 production was dose-dependently downregulated, whereas IL-12 was dose-dependently upregulated [44]. Another study showed that the impact of consuming dairy yogurt containing L. paracasei significantly increased NK cell activity, IL-12, IFN- $\gamma$, and immunoglobulin (Ig) G1 levels [45]. According to the results of this study, HY7017 works similarly to the previously known immunomodulatory effect of Lactobacillus paracasei, and also has a unique characteristic that can improve efficacy by culturing in a medium supplemented with RGE. The immune-enhancing effect of ginsenosides is widely known, and useful ingredients of red ginseng, such as red ginseng acidic polysaccharide (RGAP), increase NK cell activity [46]. The beneficial effect of RGE on probiotics may be mediated by ginsenosides. Rg3 were detected in the cytosol of HY7017 (Figure S1), and treatment of the cytoplasmic fraction in splenocytes significantly increased IFN- $\gamma$ and NK cell activity (Figure S2). These results suggested that intracellular ginsenosides might produce the observed beneficial effect. However, the exact mechanism of how these ingredients enhance the efficacy of HY7017 cells during culture remains to be elucidated.

Probiotics exhibit various health effects on the digestive tract, intestinal microbiota, and immune system, and they are lower high cholesterol levels $[10,13,47]$. To exert beneficial effects, probiotics need to survive acid and bile transit and adhere to mucosal surfaces [48]. The survival rate of HY7017 in the GIT was better than that of ATCC25302, suggesting that the HY7017 strain is more suitable as a probiotic. The survival rate of ATCC25302 was lower when it was cultured in 3\% RGE-supplemented MRS, while the survival rate of HY7017 cultured in 3\% RGE supplemented MRS was higher in the intestinal phase (Figure 5A). This result suggests that RGE provides HY7017 with protective characteristics against $\mathrm{pH}$ or enzymes. The intestinal cell adhesion of HY7017 was $2.3 \%$, which was lower than that of ATCC25302 (4.6\%). The culture of HY7017 in 3\% RGE-supplemented MRS increased the adherence to 4.1\% (Figure 5B) but did not affect ATCC25302, indicating that the effect of RGE was beneficial to HY7017 only. Previous studies have reported that EPS caused a decrease in the adhesion of the commercial probiotic strains by competing for similar adhesion targets on the probiotic strains or attaching to the cellular surface of probiotics [49]. The increase in intestinal cell adhesion rate may be due to the EPS-reducing effect. Further research is needed to elucidate the mechanisms by which RGE specifically acts on the HY7017 strain.

\section{Conclusions}

This study suggests that supplementing culture medium with RGE promotes the growth of HY7017. Since RGE supplementation exhibits higher cell incubation and harvest efficiency, this method will be advantageous to the industrial production of probiotics. In addition, cell- and animal-based studies showed that culturing HY7017 in RGE-supplemented medium produces immune-enhancing effects; namely, increased NO, TNF- $\alpha$, and IL- 6 production from macrophages, increased IL-12, IFN- $\gamma$, and NK cell activity in splenocytes, recovery of WBC levels, IL-2 and IFN- $\gamma$ upregulation, and increased NKcell activity from immunosuppressed mice. In addition, RGE supplementation enhanced the probiotic properties of HY7017, including increased stability in the GIT and better adhesion to Caco-2 cells. These results suggest that RGE supplementation enhanced the 
physiological properties of HY7017 and that HY7017 is an effective immunomodulators as a potential probiotic.

Supplementary Materials: The following are available online at https:/ /www.mdpi.com/article/ 10.3390/fermentation7040238/s1, Figure S1: Analysis of the ginsenoside content in culture medium, culture supernatant, and cytosol fraction according to RGE concentration. Figure S2: Effect of cell fractions of HY7017 cultured in 3\% RGE-supplemented MRS on IFN- $\gamma$ secretion and splenic NK cell activity.

Author Contributions: Conceptualization, S.-J.M., S.-D.P. and J.-J.S.; formal analysis, S.-J.M. and C.H.B.; investigation, S.-J.M. and B.N.; methodology, S.-J.M. and C.-H.B.; project administration, S.-D.P.; software, S.-J.M.; supervision, J.-J.S.; validation, S.-J.M.; visualization, S.-J.M.; writing—original draft preparation. S.-J.M. and B.N.; writing-review and editing, J.-L.L. All authors have read and agreed to the published version of the manuscript.

Funding: This research received no external funding.

Institutional Review Board Statement: Animal experiments were reviewed and approved by the Institutional Animal Care and Use Committee of hy Co., Ltd.

Informed Consent Statement: Not applicable.

Data Availability Statement: The data presented in this study are available in the article.

Conflicts of Interest: The authors declare no conflict of interest.

\section{References}

1. Lee, S.M.; Bae, B.S.; Park, H.W.; Ahn, N.G.; Cho, B.G.; Cho, Y.L.; Kwak, Y.S. Characterization of korean red ginseng (Panax ginseng Meyer): History, preparation method, and chemical composition. J. Ginseng Res. 2015, 39, 384-391. [CrossRef]

2. Yu, T.; Rhee, M.H.; Lee, J.; Kim, S.H.; Yang, Y.; Kim, H.G.; Kim, Y.; Kim, C.; Kwak, Y.-S.; Kim, J.-H.; et al. Ginsenoside Rc from korean red ginseng (Panax ginseng C.A. Meyer) attenuates inflammatory symptoms of gastritis, hepatitis and arthritis. Am. J. Chin. Med. 2016, 44, 595-615. [CrossRef]

3. Xie, J.-T.; McHendale, S.; Yuan, C.-S. Ginseng and diabetes. Am. J. Chin. Med. 2005, 33, 397-404. [CrossRef] [PubMed]

4. Kim, Y.-J.; Yamabe, N.; Choi, P.; Lee, J.W.; Ham, J.; Kang, K.S. Efficient thermal deglycosylation of ginsenoside Rd and its contribution to the improved anticancer activity of ginseng. J. Agric. Food Chem. 2013, 61, 9185-9191. [CrossRef] [PubMed]

5. Kim, K.H.; Lee, D.; Lee, H.L.; Kim, C.-E.; Jung, K.; Kang, K.S. Beneficial effects of Panax ginseng for the treatment and prevention of neurodegenerative diseases: Past findings and future directions. J. Ginseng Res. 2018, 42, 239-247. [CrossRef] [PubMed]

6. Kang, S.; Min, H. Ginseng, the 'Immunity Boost': The effects of Panax ginseng on immune system. J. Ginseng Res. 2012, 36, 354-368. [CrossRef]

7. Sohn, E.-H.; Jang, S.-A.; Lee, C.-H.; Jang, K.-H.; Kang, S.-C.; Park, H.-J.; Pyo, S. Effects of korean red ginseng extract for the treatment of atopic dermatitis-like skin lesions in mice. J. Ginseng Res. 2011, 35, 479-486. [CrossRef]

8. Lee, F.C. Facts about Ginseng: The Elixir of Life; Hollym International Corp.: Elizabeth, NJ, USA, 1992; p. 104.

9. Park, J.D. Recent studies on the chemical constituents of korean ginseng (Panax ginseng C. A. Meyer). J. Ginseng Res. 1996, 20, 389-415.

10. Hill, C.; Guarner, F.; Reid, G.; Gibson, G.R.; Merenstein, D.J;; Pot, B.; Morelli, L.; Canani, R.B.; Flint, H.J.; Salminen, S.; et al. The international scientific association for probiotics and prebiotics consensus statement on the scope and appropriate use of the term probiotic. Nat. Rev. Gastroenterol. Hepatol. 2014, 11, 506-514. [CrossRef]

11. Shahidi, F. Functional Foods: Their role in health promotion and disease prevention. J. Food Sci. 2004, 69, R146-R149. [CrossRef]

12. Conway, P.L. Prebiotics and human health: The state-of-the-art and future perspectives. Food Nutr. Res. 2001, 45, 13-21. [CrossRef]

13. Sarao, L.K.; Arora, M. Probiotics, prebiotics, and microencapsulation: A review. Crit. Rev. Food Sci. Nutr. 2017, 57, 344-371. [CrossRef]

14. David, L.A.; Maurice, C.F.; Carmody, R.N.; Gootenberg, D.B.; Button, J.E.; Wolfe, B.E.; Ling, A.V.; Devlin, A.S.; Varma, Y.; Fischbach, M.A.; et al. Diet rapidly and reproducibly alters the human gut microbiome. Nature 2014, 505, 559-563. [CrossRef]

15. Ouwehand, A.C.; Kirjavainen, P.V.; Shortt, C.; Salminen, S. Probiotics: Mechanisms and established effects. Int. Dairy J. 1999, 9 , 43-52. [CrossRef]

16. Macfarlane, G.T.; Cummings, J.H. Probiotics, infection and immunity. Curr. Opin. Infect. Dis. 2002, 15, 501-506. [CrossRef]

17. Song, X.; Wu, H.; Yin, Z.; Lian, M.; Yin, C. Endophytic bacteria isolated from Panax ginseng improves ginsenoside accumulation in adventitious ginseng root culture. Molecules 2017, 22, 837. [CrossRef]

18. Lee, N.-K.; Han, K.J.; Son, S.-H.; Eom, S.J.; Lee, S.-K.; Paik, H.-D. Multifunctional effect of probiotic Lactococcus lactis KC24 isolated from kimchi. LWT-Food Sci. Technol. 2015, 64, 1036-1041. [CrossRef] 
19. Jang, S.-E.; Joh, E.-H.; Lee, H.-Y.; Ahn, Y.-T.; Lee, J.-H.; Huh, C.-S.; Han, M.-J.; Kim, D.-H. Lactobacillus plantarum HY7712 ameliorates cyclophosphamide-induced immunosuppression in mice. J. Microbiol. Biotechnol. 2013, 23, 414-421. [CrossRef] [PubMed]

20. Jung, S.H.; Hong, D.K.; Bang, S.-J.; Heo, K.; Sim, J.-J.; Lee, J.-L. The Functional properties of Lactobacillus casei HY2782 are affected by the fermentation time. Appl. Sci. 2021, 11, 2481. [CrossRef]

21. Jacobsen, C.N.; Nielsen, V.R.; Hayford, A.E.; Møller, P.L.; Michaelsen, K.F.; Pærregaard, A.; Sandström, B.; Tvede, M.; Jakobsen, M. Screening of probiotic activities of forty-seven strains of Lactobacillus spp. by in vitro techniques and evaluation of the colonization ability of five selected strains in humans. Appl. Environ. Microbiol. 1999, 65, 4949-4956. [CrossRef] [PubMed]

22. Wang, L.; Huang, Y.; Yin, G.; Wang, J.; Wang, P.; Chen, Z.-Y.; Wang, T.; Ren, G. Antimicrobial activities of asian ginseng, american ginseng, and notoginseng. Phytother. Res. 2020, 34, 1226-1236. [CrossRef]

23. Bae, H.-C.; Lee, J.-Y.; Nam, M.S. Effect of red ginseng, extract on growth of Lactobacillus sp., Escherichia coli and Listeria monocytogenes in pH controled medium. Korean J. Food Sci. Anim. Resour. 2005, 25, 257-264.

24. Nwodo, U.U.; Green, E.; Okoh, A.I. Bacterial exopolysaccharides: Functionality and prospects. Int. J. Mol. Sci. 2012, 13, 14002-14015. [CrossRef]

25. Masood, M.I.; Qadir, M.I.; Shirazi, J.H.; Khan, I.U. Beneficial effects of lactic acid bacteria on human beings. Crit. Rev. Microbiol. 2011, 37, 91-98. [CrossRef] [PubMed]

26. Foligné, B.; Deutsch, S.-M.; Breton, J.; Cousin, F.J.; Dewulf, J.; Samson, M.; Pot, B.; Jan, G. Promising immunomodulatory effects of selected strains of dairy propionibacteria as evidenced in vitro and in vivo. Appl. Environ. Microbiol. 2010, 76, 8259-8264. [CrossRef] [PubMed]

27. Paturi, G.; Phillips, M.; Jones, M.; Kailasapathy, K. Immune enhancing effects of Lactobacillus acidophilus LAFTI L10 and Lactobacillus paracasei LAFTI L26 in mice. Int. J. Food Microbiol. 2007, 115, 115-118. [CrossRef] [PubMed]

28. Tsai, Y.-T.; Cheng, P.-C.; Liao, J.-W.; Pan, T.-M. Effect of the administration of Lactobacillus paracasei subsp. paracasei NTU 101 on peyer's patch-mediated mucosal immunity. Int. Immunopharmacol. 2010, 10, 791-798. [CrossRef] [PubMed]

29. Hirayama, D.; Iida, T.; Nakase, H. The phagocytic function of macrophage-enforcing innate immunity and tissue homeostasis. Int. J. Mol. Sci. 2017, 19, 92. [CrossRef]

30. Chiou, W.F.; Chou, C.J.; Chen, C.F. Camptothecin suppresses nitric oxide biosynthesis in RAW 264.7 macrophages. Life Sci. 2001, 69, 625-635. [CrossRef]

31. Lawrence, T.; Willoughby, D.A.; Gilroy, D.W. Anti-inflammatory lipid mediators and insights into the resolution of inflammation. Nat. Rev. Immunol. 2002, 2, 787-795. [CrossRef]

32. Murakami, A.; Ohigashi, H. Targeting NOX, INOS and COX-2 in inflammatory cells: Chemoprevention using food phytochemicals. Int. J. Cancer 2007, 121, 2357-2363. [CrossRef]

33. Trinchieri, G. Interleukin-12 and the regulation of innate resistance and adaptive immunity. Nat. Rev. Immunol. 2003, 3, 133-146. [CrossRef]

34. Nakayamada, S.; Kanno, Y.; Takahashi, H.; Jankovic, D.; Lu, K.T.; Johnson, T.A.; Sun, H.-W.; Vahedi, G.; Hakim, O.; Handon, R.; et al. Early Th1 cell differentiation is marked by a Tfh cell-like transition. Immunity 2011, 35, 919-931. [CrossRef] [PubMed]

35. Smeltz, R.B.; Chen, J.; Ehrhardt, R.; Shevach, E.M. Role of IFN- $\gamma$ in Th1 differentiation: IFN- $\gamma$ regulates IL-18R $\alpha$ expression by preventing the negative effects of IL-4 and by inducing/maintaining IL-12 receptor $\beta 2$ expression. J. Immunol. 2002, $168,6165$. [CrossRef] [PubMed]

36. Hunter, C.A.; Gabriel, K.E.; Radzanowski, T.; Neyer, L.E.; Remington, J.S. Type I interferons enhance production of IFN- $\gamma$ by NK cells. Immunol. Lett. 1997, 59, 1-5. [CrossRef]

37. Vivier, E.; Nunès, J.A.; Vély, F. Natural killer cell signaling pathways. Science 2004, 306, 1517-1519. [CrossRef] [PubMed]

38. Jie, Y.H.; Cammisuli, S.; Baggiolini, M. Immunomodulatory effects of Panax Ginseng C.A. Meyer in the mouse. Agents Actions 1984, 15, 386-391. [CrossRef]

39. Lewis, S.M.; Williams, A.; Eisenbarth, S.C. Structure and function of the immune system in the spleen. Sci. Immunol. 2019, 4, 33. [CrossRef]

40. Park, H.-E.; Lee, W.-K. Immune enhancing effects of Weissella cibaria JW15 on BALB/c mice immunosuppressed by cyclophosphamide. J. Funct. Foods 2018, 49, 518-525. [CrossRef]

41. Sharma, G.; Baranwal, A.K.; Mehra, N.K. Chapter 17-The human leukocyte antigen system in human disease and transplantation medicine. In Clinical Molecular Medicine; Kumar, D., Ed.; Academic Press: Cambridge, MA, USA, 2020; pp. $309-325$.

42. Trakhtenberg, E.C. The Effects of guided imagery on the immune system: A critical review. Int. J. Neurosci. 2008, 118, 839-855. [CrossRef]

43. Ye, J.; Ortaido, J.R.; Conlon, K.; Winkler-Pickett, R.; Young, H.A. Cellular and molecular mechanisms of IFN- $\gamma$ production induced by IL-2 and IL-12 in a human NK cell line. J. Leukoc. Biol. 1995, 58, 225-233. [CrossRef]

44. Liu, Y.W.; Fu, T.Y.; Peng, W.S.; Chen, Y.H.; Cao, Y.M.; Chen, C.C.; Hung, W.L.; Tsai, Y.C. Evaluation of the potential anti-allergic effects of heat-inactivated Lactobacillus paracasei V0151 in vitro, ex vivo, and in vivo. Benef. Microbes 2015, 6, 697-705. [CrossRef]

45. Lee, A.; Lee, Y.J.; Yoo, H.J.; Kim, M.; Chang, Y.; Lee, D.S.; Lee, J.H. Consumption of dairy yogurt containing Lactobacillus paracasei ssp. paracasei, Bifidobacterium animalis ssp. lactis and heat-treated Lactobacillus plantarum improves immune function including natural killer cell activity. Nutrients 2017, 9, 558. [CrossRef] 
46. Kim, K.-S.; Pyo, S.; Sohn, E.-H. Immunomodulation of NK cell activity by red ginseng acidic polysaccharide (RGAP) in ovariectomized rats. J. Ginseng Res. 2009, 33, 99-103. [CrossRef]

47. Andersson, H.; Asp, N.-G.; Bruce, Å.; Roos, S.; Wadström, T.; Wold, A.E. Health effects of probiotics and prebiotics A literature review on human studies. Food Nutr. Res. 2001, 45, 58-75. [CrossRef]

48. Shi, L.H.; Balakrishnan, K.; Thiagarajah, K.; Mohd Ismail, N.I.; Yin, O.S. Beneficial properties of probiotics. Trop. Life Sci. Res. 2016, 27, 73-90. [CrossRef]

49. Ruas-Madiedo, P.; Gueimonde, M.; de los Reyes-Gavilán, C.G.; Salminen, S. Short communication: Effect of exopolysaccharide isolated from "Viili" on the adhesion of probiotics and pathogens to intestinal mucus. J. Dairy Sci. 2006, 89, 2355-2358. [CrossRef] 